\title{
REMOÇÃO DE COR DE SOLUÇÃO AQUOSA POR ADSORÇÃO UTILIZANDO PÓ DE SERRAGEM DE PINUS sp.
}

L. M. LUNARDI ${ }^{1}$, D. S. IKENO ${ }^{2}$, L. F. SILVA ${ }^{3}$, K. Q. de CARVALHO ${ }^{4}$, F. H. PASSIG ${ }^{5}$ e C. KREUTZ $^{6}$

${ }^{1,3}$ Universidade Tecnológica Federal do Paraná, Departamento Acadêmico de Engenharia Civil câmpus Campo Mourão (DAECI/UTFPR).

${ }^{2}$ Universidade Tecnológica Federal do Paraná, Programa de Pós-Graduação em Engenharia Civil câmpus Curitiba (PPGEC/UTFPR).

${ }^{4}$ Universidade Tecnológica Federal do Paraná, Departamento Acadêmico de Construção Civil câmpus Curitiba (DACOC/UTFPR).

${ }^{5}$ Universidade Tecnológica Federal do Paraná, Programa de Pós Graduação em Ciência e Tecnologia Ambiental (PPGCTA/UTFPR).

${ }^{6}$ Universidade Tecnológica Federal do Paraná, Departamento Acadêmico de Ambiental câmpus Campo Mourão (DAAMB/UTFPR).

E-mail para contato: laylunardi@gmail.com

RESUMO - A indústria têxtil é um setor que produz resíduos que afetam principalmente o meio aquático, pois a água é um elemento fundamental no processo de produção dos tecidos. Esse trabalho foi desenvolvido com o intuito de avaliar a capacidade de adsorção do pó de serragem Pinus sp. como adsorvente alternativo na remoção de cor de efluente têxtil. Para simular a solução aquosa foram utilizados os corantes vermelho procion, vermelho RGB reativo, vermelho de metila e uma mistura contendo $50 \%$ de vermelho de metila e $50 \%$ de azul de metileno. Os ensaios foram realizados com variação da massa do pó de serragem e da temperatura. Com os resultados experimentais foram realizados ajustes com as isoterma de adsorção de Langmuir e Freundlich. A caracterização físico-

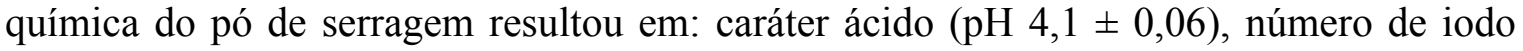
superior ao mínimo recomendado pela ABNT de $600 \mathrm{mg} / \mathrm{g}(660 \pm 0,85 \mathrm{mg} / \mathrm{g})$, densidade aparente igual a $6,15 \mathrm{~g} / \mathrm{cm}^{3}$ e teor de umidade igual a $11 \%$. A máxima remoção de cor foi de $92,04 \%$ para a mistura vermelho de metila com azul de metileno e de $58,87 \%$ para vermelho de metila. Não foi observada remoção para vermelho procion e vermelho RGB reativo, provavelmente devido à natureza reativa dos corantes, pois foi verificada remoção significativa para vermelho de metila e azul de metileno.

\section{INTRODUÇÃO}

A indústria têxtil é um setor em ascensão e é evidente a poluição gerada pelos seus efluentes, já que cerca de 20 t/ano de corantes são consumidos no Brasil e $20 \%$ são descartados como efluentes (DALlAGO; SMANIOTTO E DE OLIVEIRA, 2005). A água é um elemento indispensável no processo de produção, especialmente nas etapas de beneficiamento na qual ocorre tingimento da 


\section{9 a 22 de outubro de 2014 \\ Florianópolis/SC}

malha de algodão, com aproximadamente 120 a $180 \mathrm{~L}$ usados para cada metro de tecido final produzido (SILVA, 2007). Novos estudos têm sido desenvolvidos a fim de tratar os efluentes provenientes de indústrias têxteis que poluem visualmente a água, alteram os ciclos biológicos como a fotossíntese, além de terem compostos carcinogênicos e mutagênicos em sua composição (CÓRDOVA; DA SILVA E CÓRDOVA, 2010).

Devido à quantidade de corantes existentes e suas diferentes propriedades, existem várias formas de tratar efluentes têxteis, como processos físicos, químicos e biológicos. A adsorção pode ser dividida em física e química, porém dificilmente é possível diferenciar os tipos de adsorção, e em alguns casos, esses tipos podem ocorrer ao mesmo tempo. A eficiência deste processo está diretamente ligada ao material a ser utilizado como adsorvente e à natureza dos corantes presentes no efluente têxtil (TREVISAN et al., 2009).

Em função do custo para aquisição do carvão ativado, adsorvente mais comumente utilizado, materiais alternativos como bagaço de laranja (TREVISAN et al., 2009) e pó da cana-de-açúcar (GARCIA; BARBOSA E COSTA, 2009) tem sido investigados. O pó de serragem é um resíduo encontrado em larga escala e sem valor comercial, que foi usado por Antunes et al. (2010) com eficiência de remoção de cor de 78,8\% e por Ikeno (2013) com 81,58\%.

Dentro desse contexto, o objetivo geral deste artigo foi determinar a eficiência de remoção dos corantes sintéticos vermelho de metila, vermelho procion, vermelho remazol RGB reativo e mistura de $50 \%$ de vermelho de metila com $50 \%$ de azul de metileno por adsorção com pó de serragem de Pinus sp.

\section{METODOLOGIA}

\subsection{Material Adsorvente}

O pó de serragem Pinus sp. foi coletado em uma serraria local no município de Campo Mourão, estado do Paraná e seco durante $24 \mathrm{~h} \mathrm{a} 100{ }^{\circ} \mathrm{C}$. Foi realizada a caracterização físico-química do material adsorvente com determinação do pH (ASTM D 3838-80/1999), densidade aparente (NBR 12076/1991), número de iodo NBR 12073/1991) e teor de umidade (ASTM D 2867-04) em triplicata.

\subsection{Solução Aquosa}

Para o preparo da solução aquosa foram utilizadas soluções aquosas com concentração de 0,15 $\mathrm{g}$ de cada corante por litro de água destilada, sendo vermelho de metila $\left(\mathrm{C}_{15} \mathrm{H}_{15} \mathrm{~N}_{3} \mathrm{O}_{2} ; \mathrm{FW}=269,299\right.$; natureza $=$ vermelho em $\mathrm{pH}$ abaixo de 4,4), vermelho procion $\left(\mathrm{C}_{52} \mathrm{H}_{34} \mathrm{~S}_{8} \mathrm{O}_{26} \mathrm{~N}_{13} \mathrm{Cl}_{2} ; \mathrm{FW}=1584,38\right.$; natureza $=$ vermelho reativo $)$, vermelho remazol RGB reativo $\left(\mathrm{C}_{25} \mathrm{H}_{15} \mathrm{~N}_{7} \mathrm{O}_{16} \mathrm{~S}_{5} \mathrm{Na}_{4} \mathrm{Cl}\right.$; $\mathrm{FW}=984,82$; natureza $=$ vermelho reativo) e mistura de $50 \%$ de vermelho de metila com $50 \%$ de azul de metileno $\left(\mathrm{C}_{16} \mathrm{H}_{18} \mathrm{~N}_{3} \mathrm{SCl} ; \mathrm{FW}=319\right.$; natureza $=$ azul básico $)$. 


\subsection{Ensaios de Adsorção}

Foi determinado o comprimento de onda para cada corante na concentração de $0,15 \mathrm{~g} / \mathrm{L}$ no espectrofotômetro DR 5000 uv-vis da HACH para confeccionar a curva de calibração com diferentes concentrações de cada corante para obtenção dos valores de absorbância de cada amostra em duplicata. Com esses valores foram plotados os gráficos da absorbância em nm (eixo y) pela concentração em g/L (eixo x) para obtenção da equação da reta (ajuste linear) e do coeficiente de correlação $\left(\mathrm{R}^{2}\right)$ na ferramenta computacional Excel.

Massas de pó de serragem de $0,10,0,25,0,5,0,75 \mathrm{e} 1,0 \mathrm{~g}$ foram pesadas na balança analítica de precisão Celtac FA 2014N, e acondicionadas em erlenmeyers de $125 \mathrm{~mL}$ com solução de concentração $0,15 \mathrm{~g} / \mathrm{L}$ em $100 \mathrm{~mL}$ de cada corante. Os erlenmeyers foram colocados em uma Mesa Agitadora de Banho Metabólico Dubnoff (LABOR) e agitados a $120 \mathrm{rpm}$ durante duas horas e meia. Alíquotas de $15 \mathrm{~mL}$ foram retiradas em triplicata nos intervalos de tempo $(15,30,60,90,120,135 \mathrm{e}$ $150 \mathrm{~min}$ ) e centrifugadas por $5 \mathrm{~min}$ a $2500 \mathrm{rpm}$ na centrífuga Sislab (modelo twister) para separação da parte sólida do sobrenadante.

Com a leitura da absorbância das alíquotas no espectrofotômetro DR 5000 uv-vis da HACH, foram determinadas as concentrações de cada corante em função do tempo e calculadas as eficiências de adsorção do pó de serragem.

\subsection{Isotermas de Adsorção}

2.4.1.Isoterma experimental: Massas de 1,0 g de material adsorvente foram colocadas com $100 \mathrm{~mL}$ do efluente têxtil a $50{ }^{\circ} \mathrm{C}$ por $120 \mathrm{~min}$ na Mesa Agitadora de Banho Metabólico Dubnoff (LABOR) a $120 \mathrm{rpm}$, com concentrações da mistura de 50\% vermelho de metila e 50\% azul de metileno, em $0 ; 0,03 ; 0,1 ; 0,15$ e $0,2 \mathrm{~g} / \mathrm{L}$. Após o período de agitação, as amostras foram centrifugadas a $2500 \mathrm{rpm}$ por $5 \mathrm{~min}$, para analisar as concentrações de vermelho de metila e azul de metileno.

\subsubsection{Isoterma de Langmuir: A isoterma de Langmuir foi determinada pela Equação (1).}

$$
q=\frac{q_{\max } K_{\text {ads }} C}{1+K_{\text {ads }} C}
$$

Em que: $\mathrm{q}=$ quantidade de adsorvato (metal) retido no sólido no equilíbrio $\left(\mathrm{mg} \mathrm{g}^{-1}\right) ; \mathrm{q}_{\text {máx }}=$ é o parâmetro de Langmuir relativo à capacidade de adsorção $\left(\mathrm{mg}_{\mathrm{g}} \mathrm{g}^{-1}\right) ; \mathrm{C}=$ é a concentração do íon na solução quando esta em equilíbrio $\left(\mathrm{mg} \mathrm{L}^{-1}\right) ; \mathrm{K}_{\mathrm{ads}}=$ é a constante de Langmuir relativa à energia de adsorção (mg.g ${ }^{-1}$ ou L.mmol $\left.{ }^{-1}\right)$. 
2.4.3. Isoterma de Freundlich: A isoterma de Freundlich foi determinada pela Equação (2).

$$
q=K_{f} C^{\frac{1}{n}}
$$

Em que: $\mathrm{q}=$ quantidade de adsorvato retido no sólido no equilíbrio (mg.g $\left.\mathrm{g}^{-1}\right) ; \mathrm{C}=$ quantidade de adsorvato (metal) retido no sólido no equilíbrio $\left(\mathrm{mg}_{\mathrm{g}} \mathrm{g}^{-1}\right) ; \mathrm{K}_{\mathrm{f}}=$ coeficiente de adsorção de Freundlich; $\mathrm{n}=$ parâmetro adimensional, que indica a afinidade do solo pelo soluto.

\section{RESULTADOS E DISCUSSÕES}

\subsection{Caracterização físico-química do pó de serragem Pinus sp.}

$\mathrm{Na}$ Tabela 1 é apresentado um resumo das médias dos resultados obtidos na caracterização físico-química.

Tabela 1. Características físico-químicas do pó de serragem

\begin{tabular}{|c|c|}
\hline Características & Valores \\
\hline $\mathbf{p H}$ & $4,1 \pm 0,06$ \\
\hline Densidade Aparente (g/cm $\mathbf{3})$ & $6,15 \pm 0,53$ \\
\hline Número de Iodo (mg/g) & $660 \pm 0,85$ \\
\hline Teor de umidade (\%) & $11 \pm 1,0$ \\
\hline
\end{tabular}

\subsection{Vermelho de metila}

$\mathrm{Na}$ Tabela 2 são apresentados os resultados de eficiência de remoção (adsorção) (\%) do corante vermelho de metila submetido a temperatura de $30^{\circ} \mathrm{C}, 40^{\circ} \mathrm{C}$ e $50^{\circ} \mathrm{C}$ em função da variação da massa do adsorvente e do tempo.

Tabela 2. Eficiência de remoção de cor $(\%)$ a $30^{\circ} \mathrm{C}, 40^{\circ} \mathrm{C}$ e $50^{\circ} \mathrm{C}$.

\begin{tabular}{|c|c|c|c|c|c|c|c|c|c|c|c|c|c|c|}
\hline \multirow{2}{*}{$\begin{array}{c}\text { Tempo } \\
(\mathbf{m i n})\end{array}$} & \multicolumn{4}{|c|}{ Massa de Pó de Serragem (g) } & \multicolumn{4}{c|}{ Massa de Pó de Serragem (g) } & \multicolumn{3}{|c|}{ Massa de Pó de Serragem (g) } \\
\cline { 2 - 15 } & $\mathbf{0 , 1 0}$ & $\mathbf{0 , 2 5}$ & $\mathbf{0 , 5 0}$ & $\mathbf{0 , 7 5}$ & $\mathbf{1 , 0 0}$ & $\mathbf{0 , 1 0}$ & $\mathbf{0 , 2 5}$ & $\mathbf{0 , 5 0}$ & $\mathbf{0 , 7 5}$ & $\mathbf{1 , 0 0}$ & $\mathbf{0 , 1 0}$ & $\mathbf{0 , 5 0}$ & $\mathbf{0 , 7 5}$ & $\mathbf{1 , 0}$ \\
\hline $\mathbf{1 5}$ & 16,35 & 3,43 & 18,34 & 6,03 & 14,44 & 0,00 & 0,00 & 0,00 & 0,00 & 15,88 & 0,00 & 17,21 & 26,56 & 43,39 \\
\hline $\mathbf{3 0}$ & 0,00 & 22,62 & 16,38 & 13,00 & 33,67 & 0,00 & 0,00 & 0,00 & 1,16 & 29,88 & 0,00 & 14,42 & 36,18 & 51,58 \\
\hline $\mathbf{6 0}$ & 6,21 & 17,82 & 16,53 & 20,68 & 42,07 & 0,00 & 4,69 & 0,00 & 15,02 & 53,40 & 0,00 & 6,31 & 44,91 & 51,87 \\
\hline $\mathbf{9 0}$ & 3,71 & 10,43 & 27,42 & 16,93 & 44,38 & 0,00 & 10,20 & 0,00 & 16,45 & 58,87 & 0,00 & 0,92 & 38,47 & 55,36 \\
\hline $\mathbf{1 2 0}$ & 0,00 & 22,79 & 26,78 & 28,72 & 2,21 & 0,00 & 0,00 & 0,00 & 16,81 & 20,05 & 0,00 & 25,05 & 37,83 & 54,48 \\
\hline
\end{tabular}




\begin{tabular}{|l|l|l|l|l|l|l|l|l|l|l|l|l|l|l|}
\hline $\mathbf{1 3 5}$ & 0,00 & 26,84 & 7,77 & 33,17 & 43,59 & 0,00 & 0,00 & 0,00 & 18,29 & 47,68 & 0,00 & 8,45 & 34,36 & 56,49 \\
\hline $\mathbf{1 5 0}$ & 0,19 & 16,87 & 23,81 & 22,08 & 45,00 & 0,00 & 0,00 & 0,00 & 18,64 & 55,00 & 0,00 & 8,42 & 32,30 & 51,00 \\
\hline
\end{tabular}

O melhor resultado de eficiência de remoção obtido nos ensaios foi de 58,87\% com $1,0 \mathrm{~g}$ de pó de serragem à temperatura de $40{ }^{\circ} \mathrm{C}$ no tempo de $90 \mathrm{~min}$.

\subsection{Vermelho remazol e vermelho $\mathrm{RGB}$ reativo}

A maior porcentagem de remoção de cor foi de 2,76\% com massa de $0,50 \mathrm{~g}$ de pó de serragem à temperatura de $30{ }^{\circ} \mathrm{C}$ em 135 min de experimento. Considerando que menos de $3 \%$ da cor inicial foi removida pelo material adsorvente, foi possível concluir que o mesmo não foi eficiente. As porcentagens de remoção constam na Tabela 3.

Tabela 3. Eficiência de remoção de cor $(\%)$ a $30{ }^{\circ} \mathrm{C}, 40{ }^{\circ} \mathrm{C}$ e $50{ }^{\circ} \mathrm{C}$.

\begin{tabular}{|c|c|c|c|c|c|c|c|c|c|c|c|c|c|c|c|c|}
\hline \multirow{2}{*}{$\begin{array}{c}\text { Tempo } \\
(\mathbf{m i n})\end{array}$} & \multicolumn{9}{|c|}{ Massa de Pó de Serragem (g) } \\
\cline { 2 - 14 } & $\mathbf{0 , 1 0}$ & $\mathbf{0 , 2 5}$ & $\mathbf{0 , 5 0}$ & $\mathbf{0 , 7 5}$ & $\mathbf{1 , 0 0}$ & $\mathbf{0 , 1 0}$ & $\mathbf{0 , 2 5}$ & $\mathbf{0 , 5 0}$ & $\mathbf{0 , 7 5}$ & $\mathbf{1 , 0 0}$ & $\mathbf{0 , 1 0}$ & $\mathbf{0 , 2 5}$ & $\mathbf{0 , 5 0}$ & $\mathbf{0 , 7 5}$ & $\mathbf{1 , 0 0}$ \\
\hline $\mathbf{1 5}$ & 1,00 & 0,98 & 2,14 & 0,99 & 0,39 & 0,36 & 1,43 & 1,77 & 0,48 & 0,00 & 1,69 & 3,12 & 2,75 & 1,22 & 0,00 \\
\hline $\mathbf{3 0}$ & 1,07 & 0,85 & 2,07 & 1,14 & 0,67 & 0,56 & 1,32 & 1,76 & 0,35 & 0,00 & 1,49 & 2,60 & 2,55 & 1,18 & 0,12 \\
\hline $\mathbf{6 0}$ & 0,86 & 0,64 & 2,48 & 1,11 & 0,30 & 1,29 & 1,47 & 1,75 & 0,27 & 0,00 & 1,26 & 3,27 & 2,43 & 1,05 & 0,00 \\
\hline $\mathbf{9 0}$ & 1,29 & 0,44 & 2,23 & 0,96 & 0,00 & 1,01 & 1,32 & 1,58 & 0,09 & 0,00 & 1,26 & 3,32 & 2,44 & 0,99 & 0,14 \\
\hline $\mathbf{1 2 0}$ & 1,87 & 1,03 & 2,56 & 1,38 & 0,34 & 1,60 & 1,76 & 1,75 & 0,22 & 0,00 & 1,31 & 3,46 & 2,57 & 1,10 & 0,14 \\
\hline $\mathbf{1 3 5}$ & 1,72 & 0,59 & 2,76 & 1,43 & 0,29 & 1,70 & 1,32 & 1,67 & 0,35 & 0,00 & 1,47 & 3,41 & 2,71 & 1,22 & 0,32 \\
\hline $\mathbf{1 5 0}$ & 2,05 & 0,72 & 2,62 & 1,36 & 0,13 & 1,34 & 1,36 & 1,61 & 0,07 & 0,00 & 1,19 & 3,04 & 2,26 & 1,22 & 0,34 \\
\hline
\end{tabular}

\subsection{Vermelho procion}

Os resultados obtidos nos ensaios não indicaram eficiência de remoção para este corante. Não se tem certeza do motivo, mas a princípio seria pela natureza e propriedades químicas do corante, já que para outros corantes testados, os resultados foram eficientes com o mesmo material adsorvente.

\subsection{Mistura de vermelho de metila + azul de metileno}

Para a mistura vermelho de metila e azul de metileno, na mesma proporção, foram encontrados resultados extremamente satisfatórios. $\mathrm{O}$ pó de serragem funcionou como excelente material adsorvente. $\mathrm{O}$ melhor resultado foi obtido com $1,0 \mathrm{~g}$ de material adsorvente à temperatura de $50{ }^{\circ} \mathrm{C}$ 
em 120 min. Nessas condições de massa, temperatura e tempo, constatou-se remoção de 92,04\% da cor. Os resultados de eficiência de remoção (\%) são apresentados nas Tabelas 8, 9 e 10.

Tabela 4. Eficiência de remoção de cor $(\%)$ a $30{ }^{\circ} \mathrm{C}, 40{ }^{\circ} \mathrm{C}$ e $50^{\circ} \mathrm{C}$.

\begin{tabular}{|c|c|c|c|c|c|c|c|c|c|c|c|c|c|c|c|}
\hline \multirow{2}{*}{$\begin{array}{c}\text { Tempo } \\
\text { (min) }\end{array}$} & \multicolumn{9}{|c|}{ Massa de Pó de Serragem (g) } & \multicolumn{4}{c|}{ Massa de Pó de Serragem (g) } & \multicolumn{4}{c|}{ Massa de Pó de Serragem (g) } \\
\cline { 2 - 14 } & $\mathbf{0 , 1 0}$ & $\mathbf{0 , 2 5}$ & $\mathbf{0 , 5 0}$ & $\mathbf{0 , 7 5}$ & $\mathbf{1 , 0 0}$ & $\mathbf{0 , 1 0}$ & $\mathbf{0 , 2 5}$ & $\mathbf{0 , 5 0}$ & $\mathbf{0 , 7 5}$ & $\mathbf{1 , 0 0}$ & $\mathbf{0 , 1 0}$ & $\mathbf{0 , 2 5}$ & $\mathbf{0 , 5 0}$ & $\mathbf{0 , 7 5}$ & $\mathbf{1 , 0 0}$ \\
\hline $\mathbf{1 5}$ & 50,13 & 50,13 & 52,11 & 53,69 & 59,50 & 50,13 & 50,13 & 50,13 & 59,10 & 60,13 & 50,13 & 50,82 & 52,38 & 57,81 & 65,01 \\
\hline $\mathbf{3 0}$ & 50,13 & 50,13 & 59,00 & 60,00 & 70,41 & 50,13 & 50,13 & 55,59 & 66,86 & 70,48 & 50,13 & 51,64 & 61,00 & 66,85 & 76,85 \\
\hline $\mathbf{6 0}$ & 49,89 & 50,59 & 62,73 & 68,72 & 80,09 & 50,13 & 50,34 & 67,12 & 75,94 & 82,46 & 50,13 & 54,51 & 67,33 & 77,04 & 87,35 \\
\hline $\mathbf{9 0}$ & 50,13 & 51,12 & 64,99 & 74,49 & 82,83 & 50,13 & 50,81 & 69,64 & 77,77 & 81,37 & 50,13 & 55,87 & 70,44 & 78,49 & 87,20 \\
\hline $\mathbf{1 2 0}$ & 50,13 & 51,74 & 68,45 & 78,43 & 86,06 & 50,13 & 52,18 & 72,33 & 81,38 & 87,04 & 50,13 & 56,13 & 73,90 & 82,81 & 92,04 \\
\hline $\mathbf{1 3 5}$ & 50,13 & 52,25 & 69,98 & 79,97 & 86,32 & 50,13 & 51,19 & 74,24 & 82,39 & 88,45 & 50,13 & 58,31 & 74,00 & 82,63 & 91,59 \\
\hline $\mathbf{1 5 0}$ & 50,13 & 52,13 & 70,77 & 80,71 & 86,98 & 50,13 & 53,32 & 74,40 & 83,85 & 85,78 & 50,13 & 58,32 & 74,69 & 84,13 & 90,03 \\
\hline
\end{tabular}

\subsection{Isotermas de adsorção}

A isoterma de adsorção experimental foi realizada com a mistura de corantes vermelho de metila e azul de metileno. Escolheu-se a massa de material adsorvente de $1,0 \mathrm{~g}$, temperatura de $50{ }^{\circ} \mathrm{C}$ e tempo de 120 min para determinação das isotermas, pois estas condições indicaram os melhores resultados de eficiência de remoção $(92,04 \%)$. A curva da isoterma experimental e as curvas de Langmuir e Freundlich são apresentadas na Figura 1.

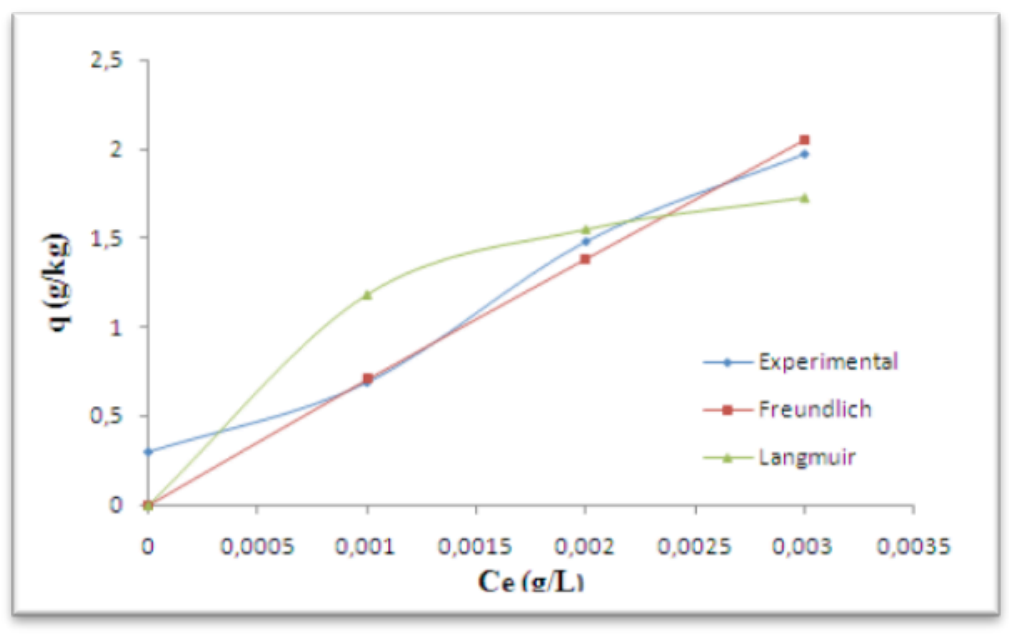

Figura 1 - Isotermas de adsorção. 
De acordo com Giles, Smith e Huitson (1974), a isoterma de adsorção experimental foi melhor ajustada na classe S, L, H e sub grupo 3, ou seja, isoterma de inflexão do platô. Barros (2000) classificou as isotermas conforme mostrado na Figura 2, de acordo com esta classificação, a curva de Langmuir é favorável e a de Freundlich é Linear.

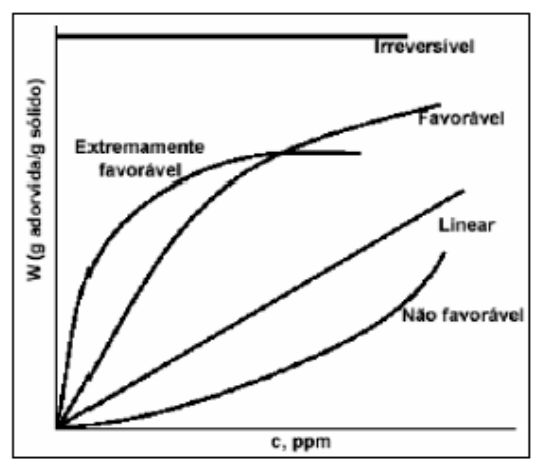

Figura 2 - Formas comuns de isoterma de adsorção. Fonte: Adaptado de Barros (2000).

\section{CONCLUSÃO}

Foi possível concluir que o pó de serragem de Pinus sp. é um adsorvente alternativo para remoção de cor de soluções aquosas contendo vermelho de metila, vermelho remazol, vermelho procion e mistura de vermelho de metila com azul de metileno. Foi constatado que o pó de serragem foi uma excelente alternativa para remoção de cor quando se usou como efluente sintético a mistura de vermelho de metila com azul de metileno, já que $92,04 \%$ da cor foi removida pelo material adsorvente.

Para o vermelho de metila, a eficiência média de remoção de cor foi de $32,2 \%$ à $30^{\circ} \mathrm{C}, 40,1 \%$ à $40{ }^{\circ} \mathrm{C}$ e $52 \%$ à $50{ }^{\circ} \mathrm{C}$ com massa de $1,0 \mathrm{~g}$ de pó de serragem. Para os corantes vermelho procion e vermelho remazol RGB reativo, os resultados foram insatisfatórios, provavelmente devido à natureza dos corantes, pois para o vermelho de metila e azul de metileno, o pó de serragem funcionou como um ótimo material adsorvente.

\section{AGRADECIMENTOS}

Os autores agradecem ao CNPq pela concessão das bolsas de iniciação científica das graduandas Layane Martins Lunardo e Lívia Fernanda Silva; e a UTFPR, câmpus Campo Mourão pela infraestrutura para realização deste trabalho. 


\section{REFERÊNCIAS}

ANTUNES, M.L.P.; CAMARGO, S.R.G. de.; JESUS, C.P.de.; RUSSO, A.C. Estudo da utilização de serragem de madeira como adsorvente para tratamento de efluentes têxteis. Estudos Ambientais., v. 12 , n. 12, p. 6-14, 2010.

BARROS, M.A.S.D. de. Remoção de metais em água utilizando diversos adsorventes. Revista Tecnológica, Ed. Especial, p. 65-72, 2000.

CÓRDOVA, F.N.; SILVA, M.M. da; CÓRDOVA, P.P. Tratamento de efluentes industriais têxteis. 2010. 19f. Conclusão de Trabalho (Curso Técnico Em Meio Ambiente na disciplina de Sistemas de Tratamento de Águas e Resíduos) - Escola de Educação Básica Dr. Otto Feuerschuette, Capivari de Baixo, 2010.

DALlAGO, R.M.; SMANIOTTO, A.; OLIVEIRA, L.C.A. de. Resíduos sólidos de curtumes como adsorventes para a remoção de corantes em meio aquoso. Revista Química Nova, v. 28, n. 3, 2005.

GARCIA, C.A.B.; BARBOSA, C.D'.A.; COSTA, E.C. Adsorção de um corante industrial utilizando um adsorvente agroindustrial in natura e tratado com $\mathrm{ZnCl}_{2}$. In: XXXIII Reunião Anual da Sociedade Brasileira de Química, 33., 2009 Águas de Lindóia. Disponível em: http://sec.sbq.org.br/cdrom/33ra/resumos/T0985-2.pdf.

GILES, C.H.; SMITH, D.; HUITSON, A. A General and Classification of Solute Adsorption Isotherm. Journal of Colloid and Interface Science, v. 47, n. 3, p. 755-765, 1974.

IKENO, D.S. Remoção de azul de metileno de efluente têxtil sintético por adsorção usando pó de serragem do gênero Pinus sp. 2013. 59 f. Monografia (Engenharia Ambiental) - Universidade Tecnológica Federal do Paraná. Campo Mourão, 2013.

SILVA, K.K.O.S. Caracterização do efluente líquido no processo de beneficiamento do índigo têxtil. 2007. 156f. Dissertação (Mestrado em Engenharia Mecânica) - Centro de Tecnologia da Universidade Federal do Rio Grande do Norte, Natal, 2007.

TREVISAN, I.J.; FERRARI, L.D.F.; ROSIN, L.E.; PEREIRA, N.C. Remoção de resíduos de efluentes têxteis utilizando processo de adsorção continua com bagaço de laranja como adsorvente. In: VIII Congresso Brasileiro de Engenharia Química em Iniciação Científica, 8., 2009 Uberlândia. Disponível em: http://www.cobeqic2009.feq.ufu.br/uploads/media/98021231.pdf. Acesso em: 21 jan. 2014. 